\title{
Development of seismic protection system for design extension conditions ${ }^{*}$
}

\author{
Ilnar I. Galiev ${ }^{1}$, Alexey N. Chernyaev ${ }^{1}$, Stanislav V. Bibik ${ }^{1}$ \\ 1 JSC "Rusatom Automated control systems", 25 Ferganskaya st., Moscow 109507, Russian Federation \\ Corresponding author: Ilnar I.Galiev (iigaliev@rasu.ru)
}

Academic editor: Yuri Korovin • Received 18 September 2018 Accepted 19 September 2018 Published 17 Ocotober 2018

Citation: Galiev II, Chernyaev AN, Bibik SV (2018) Development of seismic protection system for design extension conditions. Nuclear Energy and Technology 4(1): 43-50. https://doi.org/10.3897/nucet.4.29853

\begin{abstract}
Development of seismic protection system for design extension conditions (SPS DEC) is suggested for enhancing safety of operation of NPP located on the territories with unfavorable seismic conditions. The idea of the system consists of the creation of a network of seismic stations arranged at a certain distance from the NPP and equipped with data transmission system. In case of detection by seismic sensors of movements of the ground with magnitude of vibrations exceeding a certain preset value, seismic stations transmit over radio-channel a signal indicating exceedance of the setting before the seismic wave reaches the NPP. This allows initiating transition of the reactor to subcritical operation mode prior to the beginning of destruction of equipment and reactor building. Ensuring reliable protected communication is achieved by simultaneous use of three radio-channels arranged in accordance with TETRA, WiMAx and LTE standards, as well as by the application of appropriate cryptography, authentication and data protection methods for preventing data corruption. Analysis was performed for determining optimal distance between seismic stations and the NPP and optimal number of these stations was determined for the following two options of arrangement of seismic stations: radial arrangement surrounding the NPP and arrangement along the direction towards the place with the highest probability of earthquake incipience. Layout was suggested of multilevel majoritarian data processing for excluding false triggering of the system. Conclusions were formulated on the enhancement of safety of NPP operation and significant reduction of probability of emergency situations due to the generation of anticipatory signals to reactor shutdown systems in case of earthquakes with intensity exceeding maximum design earthquake.
\end{abstract}

\section{Keywords}

Seismic protection system, maximum design earthquake, reactor shutdown, seismic station, safety, VVER, data transmission.

\section{Prerequisites for the system development}

Accident on the Fukushima-1 NPP in Japan and its consequences demonstrated the necessity of revision of classic methods for ensuring safety of nuclear power plants and their protection from destructive effects of seismic activity (Novikova 2013, Hano 2011). In connection with the fact that NPP can be located on the territory with unfavorable seismic environment advancement of seismic protection system (SPS) is the promising direction of future development of NPP monitoring and control systems aimed at the enhancement of safety of nuclear power plants.

* Russian text published: Izvestiya vuzov. Yadernaya Energetika (ISSN 0204-3327), 2017, n.4, pp. 94-105. 
At present one of the directions of SPS development is the upgrading and expansion of networks of seismic stations (SS) for detection and registration of seismic impacts.

Seismic sensors installed on the basement plate of the reactor facility (RF) intended for continuous control of seismic impact on the NPP reactor facility and shaping discrete signal indicating the exceedance of the preset threshold of ground vibrations are included in the composition of SPS on the operated or constructed NPPs equipped with VVER reactor facilities. Seismic impacts in the form of earthquake shocks and vibrations of ground initiated both by natural causes and by artificial processes associated with human activities as well are examined. The natural causes may include tectonic, volcanic or landfall earthquakes, and explosions, filling water reservoirs or caving of mines refer to artificial causes.

As of today, equipment for NPPs under operation or construction equipped with VVER reactor facilities is selected in such a way as to ensure its operability in case of maximum design earthquake (MDE) which is determined by the specific geological conditions existing on the NPP site. In such case the possibility of earthquake with higher intensity is not considered. In other words, following the currently accepted paradigm of SPS implementation the possibility is examined of incipience of design earthquake (DE) and MDE referred to the events of the Design Basic Conditions (DBC) level, while the probability of initiation of beyond-design basis accident in case of more massive earthquakes (i.e. events of the Design Extension Conditions, DEC level) is disregarded.

In accordance with accepted norms the probability of initiation of MDE amounts to $10^{-4}$ 1/year (NP-031-01 2001). Despite this the probability of initiation of such event requires examination, because it may have disastrous consequences.

Theoretical substantiation of seismic protection system for design extension conditions (SPS DEC) representing the network of seismic stations installed at a certain distance from the NPP and equipped with the system for transmitting along the dedicated radio-channels the signal initiating power unit shutdown which is performed by introducing neutron absorbing rods in the reactor core is given in the present study. Triggering the system is anticipated in cases of incipience of earthquakes with intensities higher than that for MDE, i.e. in the conditions of initiation of events not identified by the design (DEC level).

The idea of creation of the network of remote seismic stations is exposed in (Heaton 1985). The suggested model of computer-based alarm system signaling seismic threat is intended for issuing warning signals to the NPP in case of incipience of massive earthquakes.

\section{Composition of the system}

Composition of the SPS DEC includes seismic sensors, modules for reception and processing of signals from seismic sensors at the seismic station, cable lines for transmitting signals from seismic sensors to seismic stations, device for transmission of radio-signals and module for signal reception and processing directly at the NPP.

Seismic sensors of the SPS DEC are installed radially at the distance of 5-10 $\mathrm{m}$ from seismic station at a certain depth underground in protected structures. Each seismic sensor includes three accelerometers for registration of seismic impacts and shaping discrete emergency signals warning about the exceedance of the preset level of seismic load and discrete signal indicating functionality of the sensor. In case of detection of movement of the ground with magnitude of vibrations in excess of a certain setting seismic stations transmit via radio-channels signal indicating the exceedance of the setting before the time moment when seismic wave reaches the NPP. This allows initiating conversion of reactor operation mode to subcritical state prior to the destruction of equipment and buildings. Shutting down of the power unit is implemented using technical means of the existing SPS.

Electricity supply of the seismic station is provided from external electric power supply grids or from solar panels and wind generators, as well as using batteries guaranteeing standalone operation of the system during 24 hours in case of disruption of external electricity supply.

For ensuring protection of the seismic station it is suggested to install the building of the seismic station on seismic protectors (Shustov et al. 2007). Shielded versions of cables, as well as flexible protective armor resistant against bending and tensile breaking can be applied for protection of communication lines.

\section{Communication issues between NPP and seismic stations}

Communication between NPP and seismic stations must be protected, it must possess high reliability and exclude initiation of false triggering. Ensuring reliability, as well as protection against false triggering is achieved by parallel use of three radio-channels organized in accordance with TETRA (Chivilev 2009), WiMAx (Sjuvatkin et al. 2005) and LTE (Tihvinskij et al. 2010) standards and technologies. Main technical characteristics of these standards are presented in Table 1.

Exclusion of false triggering is achieved by application of multilevel majoritarian voting (Fig. 1). Majoritarian voting of input signal from seismic sensors is performed on the first level using "two out of three" logic. Majoritarian voting of signals received from the same seismic station via each of the three radio-channels is performed according to "two out of three" logic on the second level. SPS activating signals received from different seismic stations are subjected on the third level to majoritarian voting according to "two out on N" logic. Activation of SPS must take place only after reception of signals from two or more different seismic stations for excluding false triggering because of local external effects.

Protection of data transmitted through radio-channel is ensured using VPN technologies (Roslyakov 2006) with 
Table 1. Main technical characteristics of the applicable communication standards.

\begin{tabular}{|c|c|c|c|}
\hline Communication standard & TETRA & WiMax & LTE \\
\hline Operating frequency & $150-900 \mathrm{MHz}$ & $2-11 \mathrm{GHz}$ & $1.4-20 \mathrm{GHz}$ \\
\hline Range of action & $\mathrm{Up}$ to $60 \mathrm{~km}$ & $\mathrm{Up}$ to $50 \mathrm{~km}$ & Up to $100 \mathrm{~km}$ \\
\hline Data transmission rate & Up to $28 \mathrm{kbit} / \mathrm{s}$ & Up to $70 \mathrm{Mbit} / \mathrm{s}$ & Up to $100 \mathrm{Mbit} / \mathrm{s}$ \\
\hline Supplementary information & $\begin{array}{l}\text { Data scrambling is achieved in the form of digital pro- } \\
\text { cessing of low bit rate data stream which allows applying } \\
\text { complex algorithms with high cryptographic immunity } \\
\text { not impairing quality of recovered data }\end{array}$ & $\begin{array}{l}\text { Expanded capability of } \\
\text { operation beyond direct } \\
\text { visibility }\end{array}$ & $\begin{array}{l}\text { Optimal realization of } \\
\text { required characteristics }\end{array}$ \\
\hline
\end{tabular}

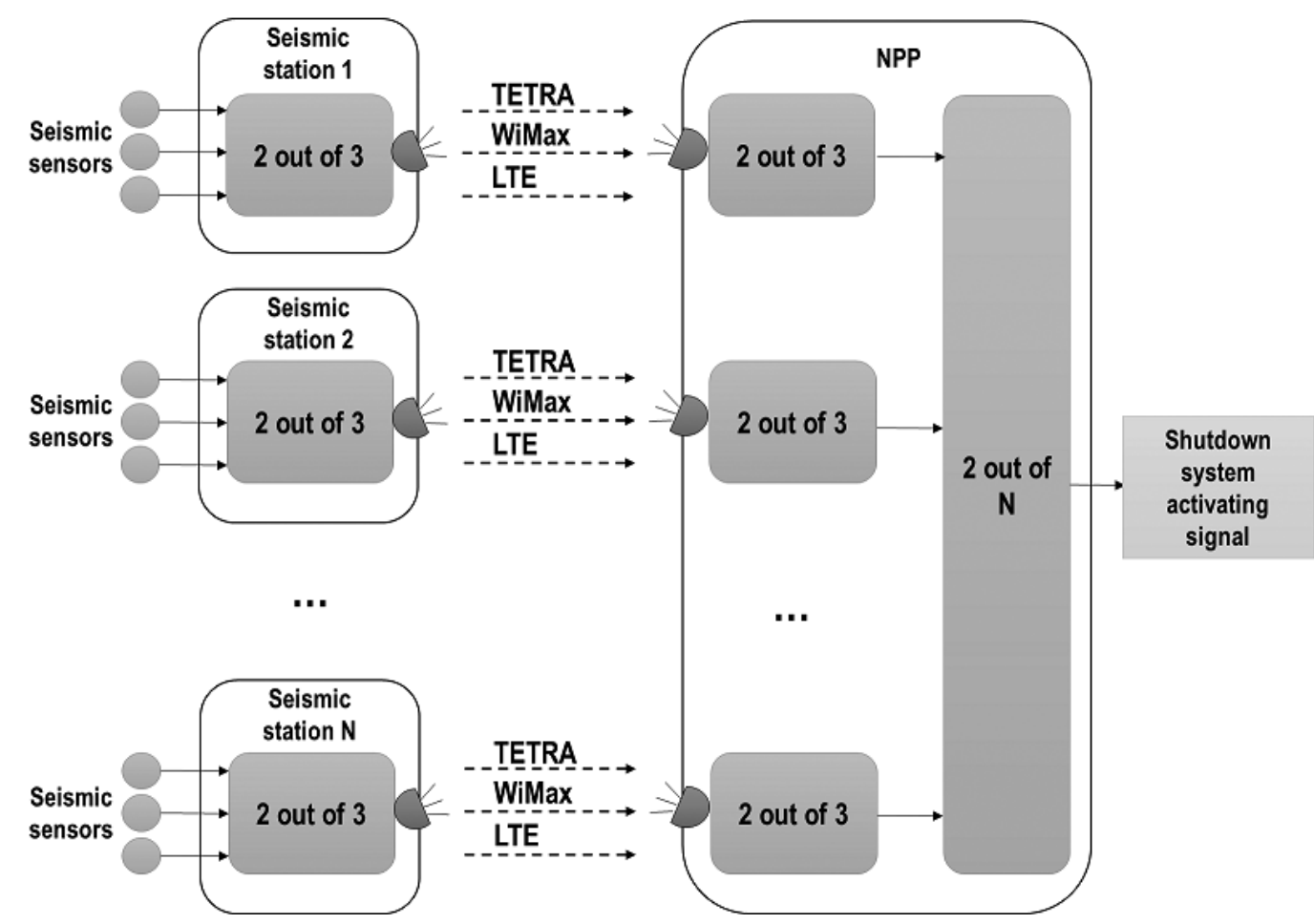

Figure 1. Organization of communications between NPP and seismic station.

application of cryptography, authentication and methods for data protection for preventing data corruption. One of the methods for protection of communications is the use of a set of protocols defined by the IP Security (IPsec) standard. Protocols of the IPSec standard are applied by such cryptographic algorithms as DES, TripleDES, AES, SHA, MD5 (Ljasin and San'kov 2005). Other standards can be applied as well for establishing communications.

\section{Topology of arrangement of seismic stations}

The main factor predetermining efficiency of the system is the higher rate of propagation of radio-waves as compared to seismic waves. The criterion of efficiency in such case is the event of transition of the reactor to subcritical operation mode before the moment when seismic wave reached the NPP site.

For reactor facilities of VVER type the design time for insertion of CPS rods in the reactor core amounts, as a rule, to not more than $4 \mathrm{~s}$. Total time available for registration of the earthquake, processing and transmission of the data to NPP, reception and processing emergency signal directly at the NPP, was well as time for shaping control action and operation of mechanisms must be not more than $2 \mathrm{~s}$. Thus, time margin $t_{\lim }$ from the moment of registration of the earthquake (reception of signal of exceedance of the established threshold value of movement of the ground) until the moment when seismic wave reaches the NPP site must be not less than $6 \mathrm{~s}$. In other words, removal of seismic stations and seismic sensors at longer distances away from the NPP must be such that the time needed for seismic wave for covering this distance will amount to not less than $t_{\text {lim }}=6 \mathrm{~s}$.

Intensity of earthquake $I$ is the intensity of vibrations of the ground on the earth surface representing the destructive force of the earthquake. It depends on the magnitude $(M)$, distance from the epicenter $(S)$ and the depth of the earthquake source $(H)$. Intensity of earthquake (in magnitude points) at the given point of the earth surface is determined by the following dependence (Gorishnij et al. 2009): 


$$
I=3+1,5 M-\lg \sqrt{S^{2}+H^{2}},
$$

where 3 and 1.5 are the regional constants (calculation was performed on the RF territory). Let us express $M$ :

$$
M=\left(I-3+\lg \sqrt{S^{2}+H^{2}}\right) / 1.5 .
$$

Taking into account that mean value of MDE intensity is equal to seven and minimum depth of occurrence of the epicenter $H=30 \mathrm{~km}$, we plot dependence $M(S)$ of earthquake magnitude on the distance between the NPP and the epicenter for which intensity of the earthquake on the NPP site is equal to seven points (Fig. 2):

$$
M(S)=\left(4+\lg \sqrt{S^{2}+30^{2}}\right) / 1,5 .
$$

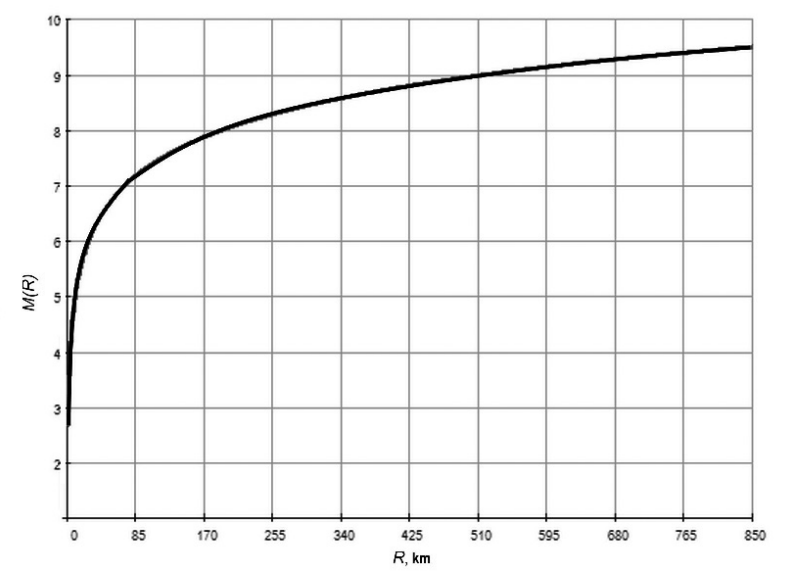

Figure 2. Dependence of magnitude of the earthquake on the distance to the NPP at which intensity of the earthquake on the NPP site is equal to seven points.
Conclusion can be drawn from analysis of the obtained dependence that in the case of incipience of earthquake with magnitude equal to 9.5 (theoretically maximum value of magnitude) at the distance of $850 \mathrm{~km}$ from the NPP site vibrations will occur on the site corresponding to intensity equal to seven points (postulated MDE).

Taking into account implementation of procedures for analyzing seismic threat during the selection of NPP construction site, subsequent analysis will be conducted by us taking into consideration incipience of the earthquake epicenter at the minimal distance of $100 \mathrm{~km}$ (SP 151.13330.2012 2013).

In the examination of 850-kilometer zone of possible incipience of earthquake and uniform distribution of epicenters probability of incipience of earthquake within the 100-kilometer zone is equal to

$$
p=S_{r=100} / S_{R=850}=\left(\mathrm{p} r^{2}\right) /\left(\mathrm{p} R^{2}\right)=100^{2} / 850^{2}=0.014
$$

Mutual location of elements of the system, as well as distances between them are schematically shown in Fig. 3. Since the distance between power units on the NPP site is much less than the distance from NPP to the seismic station, NPP site will be hereinafter treated by us as a point object. Let us note that separate data reception and processing modules are anticipated for each power unit at the NPP. Taking into account the necessity of ensuring the preset time margin the following condition of minimum efficiency of the notification system can be formulated:

$$
T_{\lim }=t_{S}-t_{A H}=(S-A H) / V,
$$

where $t_{S}$ is the time needed for seismic wave to reach the NPP site; $t_{A H}$ is the time needed for seismic wave to reach the seismic station; $V$ is the seismic wave velocity.

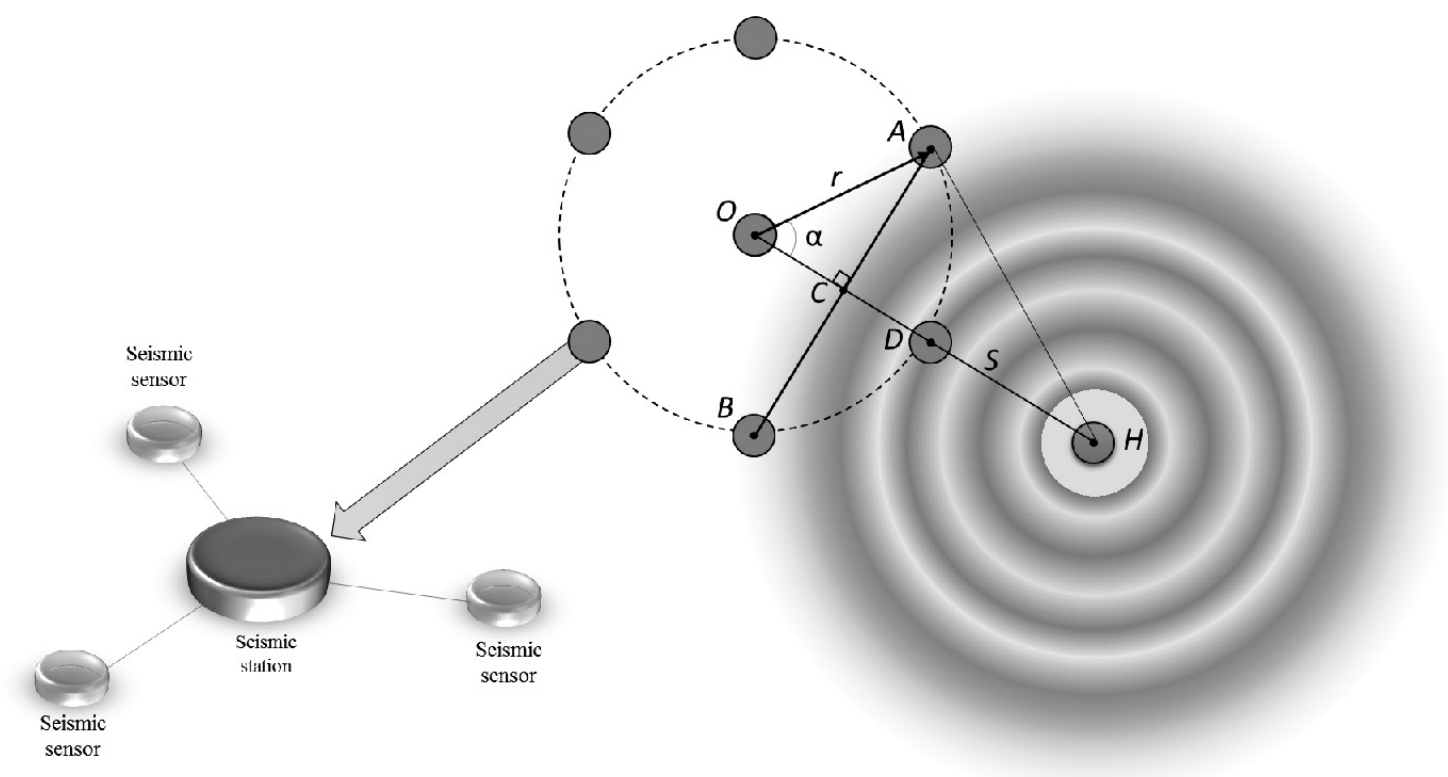

Figure 3. Simplified layout of mutual arrangement of SPS elements and epicenter of the earthquake: $O$ is the nuclear power plant; $A, D$, $B \ldots$ are the seismic stations; $H$ is the epicenter of the earthquake, $r=O A$ is the distance from the NPP to the seismic station; $S=O H$ is the distance from NPP to the epicenter of the earthquake; $A H$ is the distance from the epicenter to the seismic station. 
Velocity of S-waves carrying the greatest energy of the earthquake equal to $V \gg 3.4 \mathrm{~km} / \mathrm{s}$ is taken to be the velocity of the seismic wave $V$. Taking into account that $A H=\left(r^{2}+S^{2}-2 r S \cos a\right)^{1 / 2}$ and a $=360^{\circ} / n$, where $n$ is the number of seismic stations (for the case of uniform arrangement), we obtain

$$
T_{\lim }=\left[S-\left(r^{2}+S^{2}-2 r S \cos \left(360^{\circ} / n\right)\right)^{1 / 2}\right] / V .
$$

Solving quadratic equation we express $r(n, S)$ from the above formula as follows:

$$
\begin{gathered}
r(n, S)=\operatorname{Scos}\left(360^{\circ} / n\right)+\left[2 \left(S^{2} \cos \left(720^{\circ} / n\right)+S^{2}-\right.\right. \\
\left.\left.-2 V^{2} t_{\lim }{ }^{2}-4 S V t_{\lim }\right)\right]^{1 / 2} / 2 .
\end{gathered}
$$

Substituting the preset value of $t_{\lim }=6 \mathrm{~s}$ and $V \gg 3.4$ $\mathrm{km} / \mathrm{s}$ we obtain the dependence between the distance $r$ from the NPP to the seismic station, distance $S$ from the NPP to the epicenter of the earthquake and the number of seismic stations $n$. Graphs of this dependence are plotted in Figure 4 for different numbers of seismic stations varying from 5 to 12 . Adding $n$ as the third dimension we obtain three-dimensional graph of dependence $r(n, S)$ (Fig. 5).

Minimum distances from seismic station to the NPP are presented in Table 2 for different numbers of seismic stations. It follows from the table that the system consis- ting of seven seismic station ensures the required time for issuing preliminary warning but, however, the required distance of the seismic station from the NPP $r=47.3 \mathrm{~km}$ is too large. In such case the system consisting of eight seismic stations ensures realization of the preset requirements at the distance of $34 \mathrm{~km}$ from the NPP. Increase of the number of seismic stations to more than eight does not produce significant effect on the time for preliminary notification but, however, expenditures on construction of additional seismic stations are significantly increased. Option of implementation of SPS DEC with arrangement

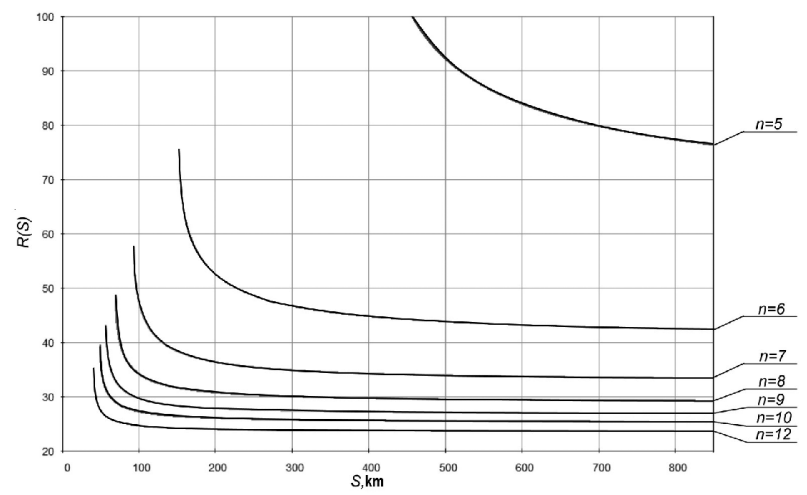

Figure 4. Dependence of the distance between NPP and seismic station on the distance from NPP to epicenter of the earthquake for different numbers of seismic stations.

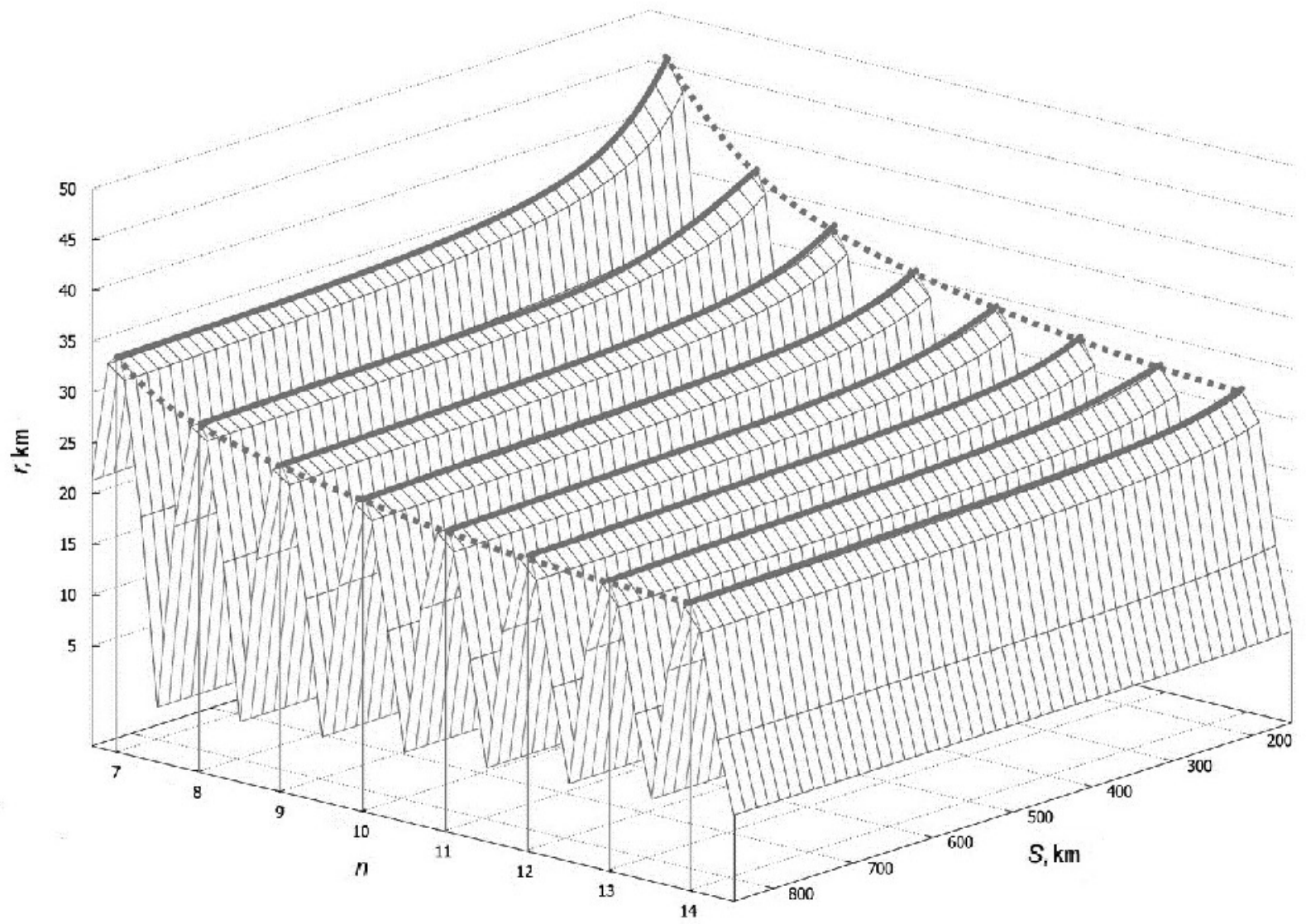

Figure 5. Three-dimensional graph of dependence of the distance from NPP to seismic station for different numbers of seismic stations. 
Table 2. Required minimum distance from seismic stations to NPP for different numbers of seismic stations.

\begin{tabular}{lcccccccc}
\hline Number of seismic stations $(\boldsymbol{n})$ & 5 & 6 & 7 & 8 & 9 & 10 & 12 \\
Radius separating seismic station from NPP $(\boldsymbol{r}, \mathbf{k m})$ & $-*$ & $-*$ & 47.3 & 34.1 & 29.6 & 27.2 & 24.7 \\
\hline
\end{tabular}

$*$ It is impossible to ensure the correlation for $t_{\lim }=6 \mathrm{~s}$ for the number of seismic stations equal to $n=5$ and $n=6$ for the preset conditions

of equipment of seismic stations in the premises of posts of the automated radiation monitoring and control system (ARMCS) located at approximately the same distances from the NPP is possible in this case (Obukhov 2017).

The suggested solution can be varied depending on different input conditions of the design, customer's requirements, geographical, geological and other conditions. For instance, the alternative method of arrangement of seismic stations is their arrangement along the direction of boundaries of lithospheric plates which is predetermined by higher probability of incipience of earthquake specifically within this area. Layout of such arrangement is represented in Fig. 6.

Let us determine the required distance $r$ between the line along which seismic stations are arranged and the NPP, as well distance $x$ between seismic stations ensuring fulfillment of the condition $t_{\lim }{ }^{3} 6 \mathrm{~s}$. Taking into account that triggering the system is envisaged only upon reception of signals of exceedance of the setting from two seismic stations, calculation will be performed for the distance from the NPP to the seismic station equal to $A H$. Similar to the calculation for radial arrangement of seismic stations minimal distance from the epicenter to the NPP $S=100 \mathrm{~km}$ will be accepted. Then, taking into account that $A H=\left[x^{2}+(S-r)^{2}\right]^{1 / 2}$, we express the distance $x(r)$ :

$$
x(r)=\left[\left(S-t_{\lim } \times V\right)^{2}-(S-r)^{2}\right]^{1 / 2} .
$$

Dependence $x(r)$ is presented in Fig. 7. Analyzing the dependence, we can draw conclusion that if seismic stations are arranged at the distance $r=24 \mathrm{~km}$ from the NPP it is sufficient to arrange them at the distance equal to 10

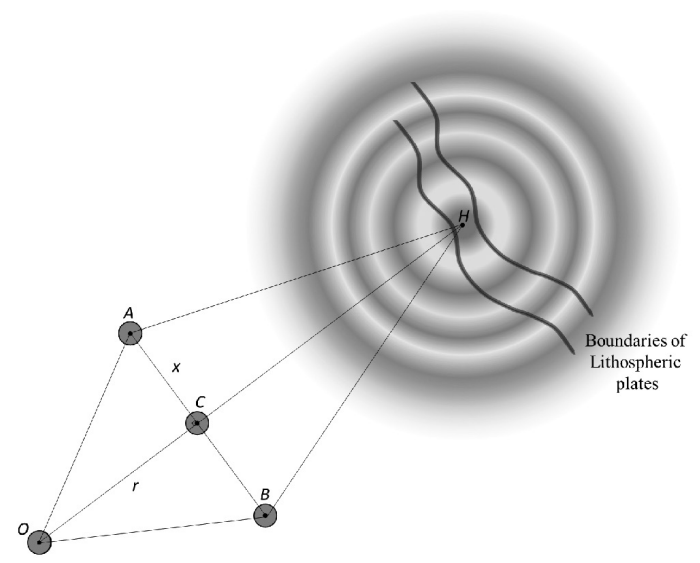

Figure 6. Arrangement of seismic stations along the direction of boundaries of lithospheric plates: $O-\mathrm{NPP} ; A, B, C \ldots-$ seismic stations; $H$ - epicenter of the earthquake; $r=O C$-distance from the NPP to the line along which the seismic stations are located; $\mathrm{S}=\mathrm{OH}$ - distance from NPP to the epicenter of the earthquake; $x=A C$ is the distance between seismic stations. $\mathrm{km}$ from each other for achieving the preset $t_{\text {lim }}$. When the epicenter is located at the distance exceeding $100 \mathrm{~km}$ such arrangement will also satisfy the condition $t_{\lim }{ }^{3} 6 \mathrm{~s}$. Distance between seismic stations equal to $10 \mathrm{~km}$ allows excluding false triggering caused by local effects occurring in the vicinity of the seismic station.

Comparative characteristics of the examined options of arrangement of seismic stations are given in Table 3 .

\section{Discussion and conclusions}

Option is suggested in the present paper of the seismic protection system for design extension conditions which, in case of incipience of earthquake with intensity larger than that for postulated MDE, i.e. in the conditions of potential development of design-basis accident, will allow performing timely activation of shutdown systems of power unit of the NPP before seismic wave reaches the NPP site, which will allow excluding the possibility of disastrous consequences.

The following two options of arrangement of seismic stations around the NPP are suggested: radial around the NPP and along the direction towards the place with the highest probability of incipience of earthquake. For fulfilling the efficiency criterion $\left(t_{\lim }=6 \mathrm{~s}\right)$ it is necessary to arrange 8 seismic stations around the NPP along the perimeter with radius equal to $34 \mathrm{~km}$. In this case equipment of seismic stations can be installed in the premises of ARMCS posts located at approximately the same distance from the NPP.

In the second case installation of three seismic stations arranged along the line parallel to the boundary of

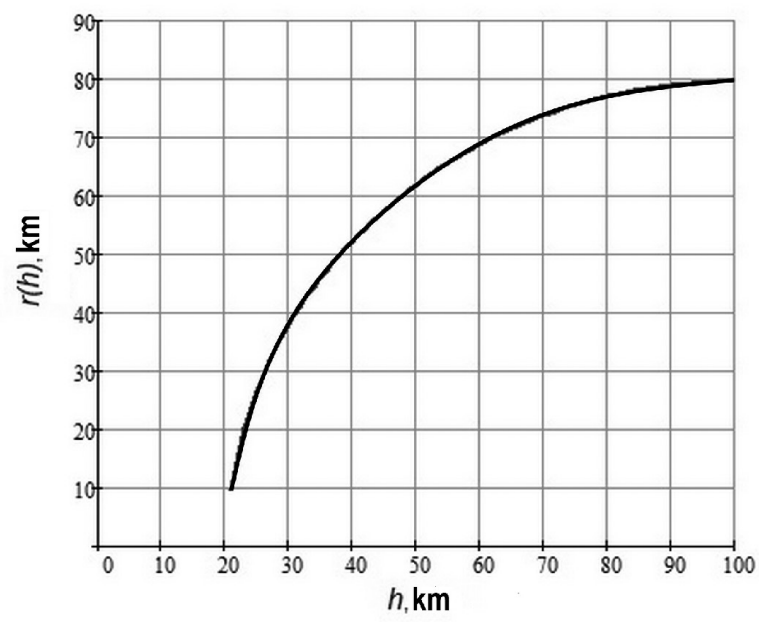

Figure 7. Dependence of distance from the line along which seismic stations are arranged and distance between seismic stations corresponding to the preset $t_{\lim }$. 
Table 3. Comparative characteristics of the examined options of arrangement of seismic stations.

\begin{tabular}{lcc}
\hline Type of arrangement & Radial & Along the direction towards the boundaries of lithospheric plates \\
Required distance from the NPP, $\mathrm{km}$ & 34 & 24 \\
Number of seismic stations & 8 & Only along the direction towards potential location of the epicenter \\
Effective coverage of surface & $360^{\circ}$ & 3 \\
\hline
\end{tabular}

lithospheric plates is sufficient for ensuring the preset time for generating preliminary warning signal. This line must be located at the distance equal to $24 \mathrm{~km}$ from the NPP with seismic stations arranged at the distance of $10 \mathrm{~km}$ from each other. This option of arrangement significantly reduces the number of constructed seismic stations but, however, NPP becomes in this case vulnerable to earthquakes with epicenter located along different directions.

It is evident that along with the above listed factors layout of arrangement of seismic stations relative to the NPP must be determined individually for each specific case on the basis of analysis of different originally stipulated specifications of the project, customer's requirements, geographical, geological and other conditions.

SPS DEC is a flexible system allowing incorporating any number of seismic stations, different topologies and different options of organization of data transmission network. Application of meshed topology of the network differing from other types of architecture by enhanced reliability of communication is possible. Such reliability is achieved due to the fact that every network node is connected with several other nodes and, simultaneously, each of the nodes can take upon itself implementation of functions of commutator for other nodes. The layout of data transmission suggested in the present paper has the following advantages:

- Simultaneous use of three protected data transmission protocols allows ensuring the required degree of protection of the network from unauthorized access. Since in order it is necessary for the perpetrator to simultaneously intrude two protected data communication channels for each seismic station in order to shape false signal activating the system, which is physically impossible to achieve. Seismic stations are equipped with modern security alarm equipment including motion detection sensors.

- Application of majoritarian logic according to "two out of N" logic for shaping signal triggering reactor shutdown systems ensures protection from false triggering due to the local effects such as heavy objects falling in the vicinity of the seismic station, passage of heavy trucks, railroad cars, etc. Use of information from motion detection sensors as part of the algorithm of system operation allows as well to prevent false triggering of the systems in case of intentional local effects initiated by perpetrators within the zone of location of seismic stations.
- Application of majoritarian logic according to "two out of N" logic for input signals from seismic sensors and signals received from seismic stations through radio-channels ensures protection from false triggering initiated by individual failures of sensors and data transmission channels.

Potential individual failure in the data processing module and in the data transmission module on one of seismic stations will not disturb functioning of the SPS DEC. Seismic system transmits in real time signal to the NPP confirming operability of associated technical means. Alarm signaling failure of the seismic system is activated in the central control room of the NPP if the signal is lost. In such case maintenance personnel is promptly directed to the seismic station for eliminating causes of the failure. If, nevertheless, initiating events occur during this time period (i.e. earthquakes of appropriate force), they are registered by adjoining seismic stations ensuring implementation of functions of the SPS DEC within the time required for triggering preliminary alarm signal.

Installation of seismic stations on seismic protectors and laying cables to seismic stations inside flexible protected cable trays allow preserving functionality of the seismic station under loads exceeding loads developed during MDE. In case of break of electric power supply lines batteries installed on seismic stations guarantee standalone operation of the SPS DEC during the preset time period.

Based on the fact that functioning of the system under discussion is needed only in the conditions not anticipated by the NPP design and fraught with emergence of beyond-design basis accidents the system can be referred to the third safety class in pursuance with NP-001-15 (NP001-15 2015) or to Safety class 3 category in accordance with IAEA SSG-30 (SSG-30 2014). Application of equipment of lower safety class as compared with safety class of the SPS for design-basis accidents allows softening requirements on the qualification of equipment with leads to significant reduction of expenditures on the realization of the system. It has to be noted that referring the system to the third class of safety does not exclude the use of wireless data transmission technologies.

Thus, conclusion can be drawn that the proposed seismic protection system is the viable option not requiring heavy expenses for its realization and allowing significantly enhancing safety of nuclear power plant due to timely signaling the beyond-design basis accidents initiated by earthquakes with intensities exceeding the MDE. 


\section{References}

- Chivilev SV (2009) Standard TETRA. Possibilities and Advantages. Elektrotehnicheskie i informacionnye kompleksy i sistemy 5(2): 50-55. [in Russian]

- Gorishnij VA, Volkov VV, Chernecov VB, Borisenko LN (2009) Assessment of the engineering environment in an emergency situation. NGTU Publ., Nizhny Novgorod, 83 pp. [in Russian]

- Hano J (2011) Das japanische Desaster: Fukusima und die Folgen. Freiburg. Herder Verlag, 160 pp.

- Heaton TH (1985) A model for a seismic computerized alert network. Science 228: 987-990. https://doi.org/10.1126/science. 228.4702 .987

- Ljasin DN, San'kov SG (2005) Methods and means of protection of computer information. VolgGTU Publ., Volgograd, 127 pp. [in Russian]

- Novikova AA (2013) The natural disaster in Japan and its consequences. INION RAN Publ., Moscow, 40 pp. [in Russian]

- NP-001-15 (2015) General provisions for ensuring the safety of nuclear power plants. Rostehnadzor Publ., Moscow. [in Russian]

- NP-031-01 (2001) The design standards of earthquake-resistant nuclear power plants. Gosatomnadzor Rossii Publ., Moscow, 33 pp. [in Russian]
- Obukhov E (2017) Ecology and nuclear energy. Ekologiya i atomnaya energetika. http://www.ecoatominf.aaanet.ru/notes/control.htm [22.04.2017] [in Russian]

- Roslyakov AV (2006) Virtual private networks. Fundamentals of construction and application. Eko-Trendz Publ., Mosccow, 304 pp. [in Russian]

- Shustov V, Basseri S, Shustov S (2007)Testing of a new line of seismic base isolators. Final Project Report to NSF, Award no 0618183 , La Crescenta, CA, 35 pp.

- Sjuvatkin VS, Esipenko VI, Kovalev IP, Suhorebrov VG (2005) Wireless technology: theoretical foundations, standards, application. BHV-Peterburg Publ., Saint Petersburg, 356 pp. [in Russian]

- SP 151.13330.2012 (2013) Engineering surveys for the location, design and construction of nuclear power plants. Part I. engineering surveys for the development of pre-project documentation (choice of point and choice of NPP site). Gosstroj Publ., Moscow. [in Russian]

- SSG-30 (2014) Safety classification of structures, systems and components in nuclear power plants. Vienna, IAEA.

- Tihvinskij VO, Terent'ev SV, Yurchuk AB (2010) LTE Mobile Networks: Technology and Architecture. Eko-Trendz Publ., Moscow, 284 pp. [in Russian] 